\section{IMPROVING THE SENSE OF WELLBEING FOR DEPENDENT OLDER PEOPLE LIVING IN SUPPORTED HOUSING}

\section{Yukiko Kuboshima ${ }^{1 *}$, Jacqueline McIntosh ${ }^{2}$, Bruno Marques ${ }^{3}$}

$1 *$ Victoria University of Wellington, ${ }^{2}$ Senior Lecturer Victoria University of Wellington, ${ }^{3}$ Lecturer Victoria University of Wellington

Yukiko.Kuboshima@vuw.ac.nz

\begin{abstract}
Internationally, supported housing, which provides dependent older people with levels of support and care in their private dwelling, has been reported to provide a greater sense of wellbeing and a superior quality of life than support in residential care facilities. However, a study indicated high levels of dissatisfaction with this form of housing in New Zealand. The aim of this study is to identify the problems of current supported housing for older people in terms of psychological well-being. The objectives are to clarify and evaluate the reasons why supported housing is deemed detrimental to older people's psychological well-being and their quality of life. A review of the literature dated from 2000 to 2015 was conducted, exploring the domestic and international literature on the quality of life of residents in long term care settings. Gathering data from a wide range of disciplines including gerontology, nursing and architecture, contents were categorised to identify key themes. The complaints with 'supported living' in retirement villages related to the 'institutional characteristics.' Concerns were distilled into four main areas: 1) an undermined sense of independence with respect to personal care; 2) the ambiguity of privacy in private rooms; 3 ) the loss of personal identity due to a reduction of private space; and 4) the limited opportunity for meaningful activity and socialisation. There are strong indications that improvements in the design of residents' private space can be key to improving their psychological wellbeing.
\end{abstract}

Keywords: supported living, retirement villages, dependent older people, well-being, aged care

\section{Introduction}

The population of older people in New Zealand is increasing. As people age, their propensity for disability increases (Statistics New Zealand, 2013) and they require more care and support (Davey and Keeling, 2004). Some older people consider moving to live closer to their children to receive care from them, but 'most would not want to live with family,' and even 'residential care was generally preferred, to avoid being a burden' (Davey, 2006a).

Residential care is a major accommodation option for frail elderly. Residential care in New Zealand includes rest homes and some type of hospitals (Ministry of Health, 2013). While the majority of older New Zealanders live in private dwellings, as they become frail, increasingly people live in residential care as shown in Figure 1 (Statistics New Zealand, 2013). The proportion of older people using residential care for late-life care was at least at $65 \%$ for those aged 85-94 (Figure 2) (Broad et al., 2015).

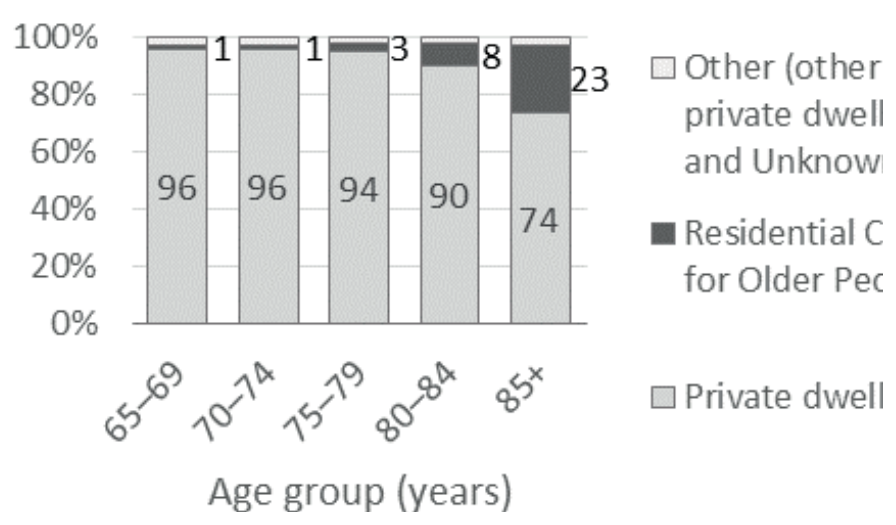

Figure 1 - Dwelling type of older people by age group

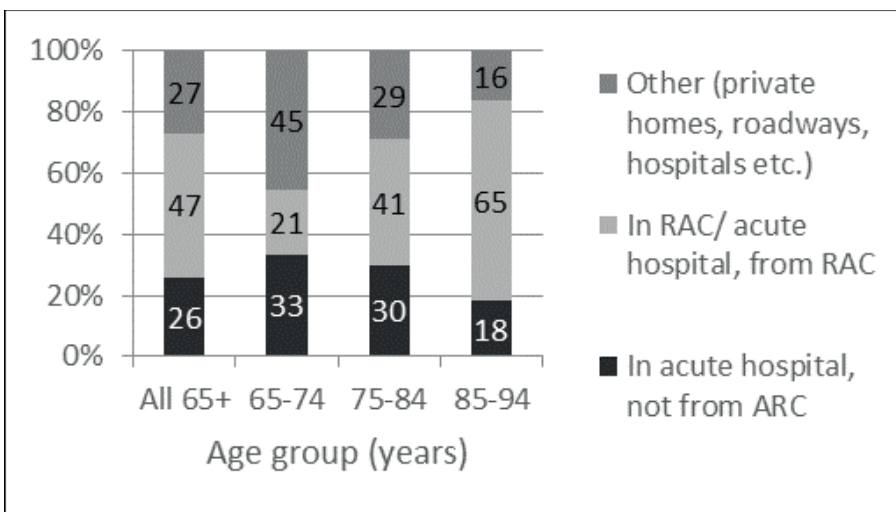

Figure 2 - Percentage of older people who felt happy and sad over the six-month period from the time of the decision on where to live

Unhappiness of residents in residential care has been reported. A study revealed that $71 \%$ of people living there for six months responded that they felt sad about the decision to move, while about $73 \%$ of those living at home with care for six months felt happy (Figure 3) (Jörgensen, 2006).

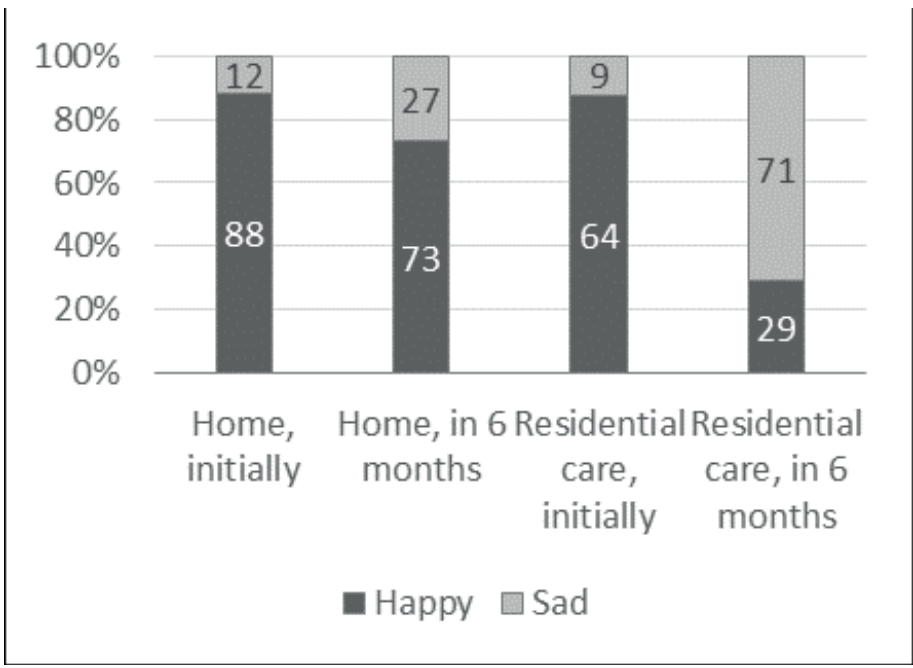

Figure 3 - Percentage of decedents and place of death in New Zealand 20062010

Supported housing has been reported to provide greater quality of life (QoL) than residential care internationally (Brandi et al., 2003). However, the experience of residents in supported housing in New Zealand is not so positive. Hayward reports that the residents in supported-living units in retirement villages perceive: a loss of privacy, independence and autonomy; poor social connections; and poor quality environments in their private rooms, compared with those living in independent-living units, who were relatively satisfied (2012). He concluded that the experiences of the residents in assisted-living do not differ 
greatly from those in residential care (Hayward, 2012). Without changes to this form of housing, the dissatisfaction of residents of supported housing and the detriment to their psychological wellbeing is also likely to increase.

Internationally, there are more housing options for the frail elderly. Rather than purely institutional settings, options have developed, such as 'sheltered housing', 'Continuing Care Retirement Communities', 'extra care housing' and 'assisted living.' In particular, there are many types of supported housing, where older people can make use of services provided through collective living options. There is currently a scarcity of supported housing options in New Zealand (Davey, 2006b).

This study aims to identify the problems of current supported housing for older people in terms of psychological well-being. The objectives are to clarify and evaluate the reasons why supported housing is deemed detrimental to older people's psychological well-being and their QoL. To do this, an extensive literature review was conducted, exploring the domestic and international literature from 2000 to 2015 on the quality of life of older people who receive long term care. The data are from a wide range of disciplines including gerontology, nursing and architecture.

\section{Findings}

As people age and have more difficulty with their mobility, they spend more time in their own home. For this reason the home becomes increasingly important for the wellbeing of older people. In addition the psychological aspects of home, which include warmth and stability, continuity, independence, identity, control and privacy, security and autonomy, safety and familiarity become greater contributors to QoL (Hale et al., 2010, Granbom et al., 2014, Dyck et al., 2005, Cooney, 2012).

In long-term care settings, care is provided as efficiently as possible to accommodate large numbers of people. As a result they typically lack core qualities of home such as occupant control, autonomy, choice, privacy and selfdetermination (Klaassens and Meijering, 2015, Granbom et al., 2014, Cooney, 2012). The individual's sense of self can be compromised as they are socialized into the care-providers' routines (Wiersma and Dupuis, 2010) where privacy is lacking and/or ambiguous (Twigg, 2002, McColgan, 2005). These characteristics of long term care settings have been associated with the word 'institutional' and have been criticized by many researchers (Goffman, 1968, Klaassens and Meijering, 2015).

Residents' loss of autonomy and privacy, which are typical institutional characteristics, can also happen in the home (Hale et al., 2010) as with supported living arrangements. The provision of care services into the home not only challenge its 'privateness'; but identities are also at stake (Dyck et al., 2005). Established meanings and routinized activities are often disturbed (Dyck et al., 2005). Spatial reorganization such as re-modeling of the kitchen or reorganizing the downstairs into a bedrooms/living area as well as relocation of material possessions which mark a social identity can make the individual feel either 'invisible' or unrecognizable as the people they used to be; their sense of home disrupted and their private space violated (Hale et al., 2010).

\section{Key themes for psychological aspects of QoL}

Much research has been done relative to key themes of QoL for older people in long-term care. In the UK, Tester et al. identified four essential needs for QoL in frail older people in institutions as; sense of self, the care environment, relationships, and activities
(2004). Similarly, Murphy et al. in Ireland revealed four thematic domains of QoL: care environment and ethos of care, personal identity, connectedness to family and community, and activities and therapies (2007).

\section{Independence}

A significant correlation between higher dependency and lower QoL has been identified (Orrell et al., 2013). Dependency in activities of daily living lowers self-esteem, self-efficacy and sense of control, especially those involving assistance in dressing and transfer (moving between wheelchair and bed), which require help many times a day (Boström et al., 2014). When personal care is provided, especially in showering, bathing and dressing, that are normally considered private tasks, people often feel a strong feeling of powerlessness (Hale et al., 2010).

\section{Privacy}

When privacy is afforded, people are able to exercise personal choice and safeguard their dignity (Bland, 1999). However, privacy is often at stake in institutional settings. Loss or ambiguity of residents' privacy in private space occurs when caregivers enter the room without waiting for permission, by their undesired presence in private spaces, by personal care being conducted in relatively public spaces, by the existence of the institutional furniture, and by the lack of space where they could be completely private (Hale et al., 2010, Nord, 2011, Nord, 2013, Klaassens and

Meijering, 2015).

\section{Personal identity}

Having an environment consistent with personal history and identity is a key factor to maintaining a positive sense of self (Perkins et al., 2012). The most visual way in which residents express their identity is through personalization of their space (Cooney, 2012). Creating personal space with their own belongings such as pictures, furniture and hobbies, or plants brought with them from their previous home provides a connection between the person they are now and the person they had been prior to moving (Murphy et al., 2007).

\section{Activities}

The significance of 'meaningful activities' has been a focus of much recent research (Wright-St Clair, 2011, Murphy et al., 2007, Kiata-Holland, 2010, Eakman et al., 2010). Maintaining the continuity of personal activities which create a sense of security, comfort and predictability were at times compromised by care routines (Cooney, 2012). The meaningfulness of activities differs by individual, and residents felt some activities offered were boring and frustrating (Tester et al., 2004). Others felt that they could not do some activities because of the absence of the adequate facilities. (Gusmano, 2004).

\section{Relationships}

As people age, some experience difficulty in maintaining relationships because of physical and cognitive impairment (Boyd et al., 2009). While some studies reported social interaction between residents positively, undesired social interaction was often reported negatively. For example, in communal areas, residents were reported as rarely talking with each other; and overall residents did not seem to want to be identified with their dependent fellow residents (Hauge and Heggen, 2008, Nord, 2013). Many residents had greater difficulty feeling a sense of 'belonging,' or being a part of the group (Cooney, 2012). Inhospitable space can impact on residents relationships as well as visits from family and friends which are valuable for older people and provide an important source of interest and social 
stimulation. (Murphy et al., 2007, Tester et al., 2004).

\section{Relationships between QoL and physical environments}

Many quantitative studies have focused on the relationships between QoL of older people and the physical environment in long-term care settings. The correlation between resident satisfaction and: facility size; personal space; physical amenities was found to be significant (Sikorska, 1999). In particular, the strong correlation between the facility size and residents' QoL was frequently reported (Torrington et al., 2004, Orrell et al., 2013).

Qualitative research into QoL and its relationship to architecture can be grouped into research with respect to; public space and private space. Internationally the focus has been on public space, describing the institutional aspects, and suggestions for improvements (Hauge and Heggen, 2008, Wojgani and Hanson, 2007). Cooney reported residents' choice was at stake because of poor building design, such as few public/collective bathrooms and limited communal space (2012). However, recently, the significance of individual private space for residents' QoL has been stressed. Hauge and Heggen argued that residents should not be denied the right to pursue their individual private life in their private rooms, not only in a public space (2008). Some studied residents' private space through the use of interviews (Hayward, 2012, Nord, 2013), and recently a study focused on privacy in residents' private rooms through observations of the delivery of care (Nord, 2011).

The situations affecting QoL in long-term care settings are classified by themes and their relevance to space (private/public) as shown in Table 1. Concerns were distilled into four main concerns: an undermined sense of independence with respect to personal care; ambiguity of privacy in private rooms; loss of personal identity due to a reduction of private space; and little opportunity for meaningful activity and socialisation.

\section{Conclusion}

Despite the situation where the home becomes more significant as the elderly age, 'institutional characteristics' of care in the home have led to loss of residents' individuality and reduced their QoL in supported housing. Through literature, the key requirements of QoL for older people in long-term care settings related to needs associated with independence and control, privacy, personal identity, activities, relationships and quality of care. Through an examination of the detailed problems, there are strong indications that improvements in the design of residents' private space can be key to improving their sense of privacy, identity and independence. However, there is a lack of knowledge with respect to the contribution of architecture to this area, as well as to supporting meaningful activities and relationships in the relationships of private and public space.

\section{References}

BLAND, R. 1999. Independence, privacy and risk: Two contrasting approaches to residential care for older people. Ageing and Society, 19, 539-560.

BOSTRÖM, G., CONRADSSON, M., ROSENDAHL, E., NORDSTRÖM, P., GUSTAFSON, Y. \& LITTBRAND, H. 2014. Functional capacity and dependency in transfer and dressing are associated with depressive symptoms in older people. Clinical Interventions in Aging, 9, 249-257.

BOYD, M., CONNOLLY, M., KERSE, N., FOSTER, S., RANDOW, M. V., LAY-YEE, R., CHELIMO, C., BROAD, J., WHITEHEAD, N. \& WALTERS-PUTTICK, S. 2009. Changes in Aged Care Residents' Characteristics and Dependency in Auckland 1988 to 2008. Findings from OPAL 10/9/8 Older Persons' Ability Level Census. Auckland: Freemasons' Department of Geriatric Medicine and The University of Auckland.

BRANDI, J. M., KELLEY-GILLESPIE, N., LIESE, L. H. \& FARLEY, O. W. 2003. Nursing Home vs. Assisted Living. Journal of Housing For the Elderly, 18, 73-88.

BROAD, J. B., ASHTON, T., GOTT, M., MCLEOD, H., DAVIS, P. B. \& CONNOLLY, M. J. 2015. Likelihood of residential aged care use

Table 1 - Problems in QoL of residents in long-term care settings

\begin{tabular}{|c|c|c|c|}
\hline \multirow{2}{*}{ Themes of QoL } & \multirow{2}{*}{ Problems } & \multicolumn{2}{|c|}{ Space } \\
\hline & & Private & Public \\
\hline $\begin{array}{l}\text { Sense of } \\
\text { independence }\end{array}$ & $\begin{array}{l}\text { Personal care (especially transferring, showering, bathing } \\
\text { and dressing) affects sense of independence }\end{array}$ & - & \\
\hline Privacy & $\begin{array}{l}\text { Ambiguity/loss of privacy in private space (caregivers } \\
\text { entering the room without waiting for permission, their } \\
\text { presence in private space, personal care in relatively public } \\
\text { space, and no place where residents could be completely } \\
\text { private) }\end{array}$ & - & \\
\hline Personal identity & Not enough space for personal belongings & • & \\
\hline $\begin{array}{l}\text { Activities and } \\
\text { relationships }\end{array}$ & $\begin{array}{l}\text { Little opportunity for meaningful activities and relationships } \\
\text { (boredom, some activities provided are boring, no adequate } \\
\text { facilities for individual meaningful activities, undesired } \\
\text { society with other residents, not enough space for hosting } \\
\text { guests personally) }\end{array}$ & - & - \\
\hline
\end{tabular}


in later life: a simple approach to estimation with international comparison. Aust N Z J Public Health, 39, 374-9.

COONEY, A. 2012. 'Finding home': a grounded theory on how older people 'find home' in long-term care settings. International Journal of Older People Nursing, 7, 188-199.

DAVEY, J. 2006a. "AGEING IN PLACE": THE VIEWS OF OLDER HOMEOWNERS ON MAINTENANCE, RENOVATION AND ADAPTATION. Social Policy Journal of New Zealand, 128-141.

DAVEY, J. 2006b. RESEARCH ON AGEING IN NEW ZEALAND: PROGRESS, GAPS, AND THE POTENTIAL CONTRIBUTION OF EWAS RESEARCH. EWAS WORKING PAPER SERIES. ENHANCING WELLBEING IN AN AGEING SOCIETY (EWAS).

DAVEY, J. \& KEELING, S. 2004. COMBINING WORK AND ELDERCARE: A NEGLECTED WORK-LIFE BALANCE ISSUE. Labour. Employment and Work in New Zealand.

DYCK, I., KONTOS, P., ANGUS, J. \& MCKEEVER, P. 2005. The home as a site for long-term care: meanings and management of bodies and spaces. Health \& Place, 11, 173-185.

EAKMAN, A. M., CARLSON, M. E. \& CLARK, F. A. 2010. The Meaningful Activity Participation Assessment: A Measure of Engagement in Personally Valued Activities. The International Journal of Aging and Human Development, 70, 299-317.

GOFFMAN, E. 1968. Asylums: Essays on the social situation of mental patients and other inmates, Great Britain, Pelican Books.

GRANBOM, M., HIMMELSBACH, I., HAAK, M., LÖFQVIST, C., OSWALD, F. \& IWARSSON, S. 2014. Residential normalcy and environmental experiences of very old people: Changes in residential reasoning over time. Journal of Aging Studies, 29, 9-19.

GUSMANO, M. K. 2004. Jacquelyn beth frank. the paradox of aging in place in assisted living / david barton smith. reinventing care: assisted living in New York city. Journal of Health Politics, Policy \& Law, 29, 1227-1234 8p.

HALE, B., BARRETT, P. \& GAULD, R. 2010. The Age of Supported Independence. Voices of In-home Care. New york: Springer.

HAUGE, S. \& HEGGEN, K. 2008. The nursing home as a home: a field study of residents' daily life in the common living rooms. Journal of Clinical Nursing, 17, 460-467.

HAYWARD, C. R. 2012. A HOME AWAY FROM HOME? : THE TRANSITIONS OF OLDER PEOPLE WITHIN TWO NEW ZEALAND RETIREMENT VILLAGES. MASTER OF ARTS IN SOCIOLOGY, THE UNIVERSITY OF CANTERBURY.

JÖRGENSEN, D. M. 2006. Factors influencing entry to residential care among older people. Doctor of Philosophy, The University of Auckland.

KIATA-HOLLAND, E. J. 2010. 'All in a day's work': The life-world of older people in New Zealand rest homes. Doctor of Philosophy in General Practice and Primary Health Care, The University of Auckland.

KLAASSENS, M. \& MEIJERING, L. 2015. Experiences of home and institution in a secured nursing home ward in the Netherlands: A participatory intervention study. Journal of Aging Studies, 34, 92-102.

MCCOLGAN, G. 2005. A Place to Sit: Resistance Strategies Used to Create Privacy and Home by People with Dementia. Journal of Contemporary Ethnography, 34, 410-433.

MINISTRY OF HEALTH 2013. Residential care questions and answers.
MURPHY, K., SHEA, E. O. \& COONEY, A. 2007. Quality of life for older people living in long-stay settings in Ireland. Journal of Clinical Nursing, 16, 2167-2177.

NORD, C. 2011. Architectural space as a moulding factor of care practices and resident privacy in assisted living. Ageing \& Society, 31, 934-952.

NORD, C. 2013. A day to be lived. Elderly peoples' possessions for everyday life in assisted living. Journal of Aging Studies, 27, 135-142.

ORRELL, A., MCKEE, K., TORRINGTON, J., BARNES, S., DARTON, R., NETTEN, A. \& LEWIS, A. 2013. The relationship between building design and residents' quality of life in extra care housing schemes. Health \& Place, 21, 52-64.

PERKINS, M. M., BALL, M. M., WHITTINGTON, F. J. \& HOLLINGSWORTH, C. 2012. Relational autonomy in assisted living: A focus on diverse care settings for older adults. Journal of Aging Studies, 26, 214-225.

SIKORSKA, E. 1999. Organizational Determinants of Resident Satisfaction With Assisted Living. The Gerontologist, 39, 450-456.

STATISTICS NEW ZEALAND 2013. 2013 Census QuickStats about national highlights - tables.

TESTER, S., HUBBARD, G., DOWNS, M., MACDONALD, C. \& MUEPHY, J. 2004. Frailty and institutional life. In: WALKER, A. \& HENNESSY, C. H. (eds.) Growing Older: Quality Of Life In Old Age: Extending quality of life. Maidenhead: Open University Press.

TORRINGTON, J., BARNES, S., MCKEE, K., MORGAN, K. \& TREGENZA, P. 2004. The Influence of Building Design on the Quality of Life of Older People. Architectural Science Review, 193197.

TWIGG, J. 2002. Bathing - the Body and Community Care: The Body and Community Care (1), Florence, US, Routledge.

WIERSMA, E. \& DUPUIS, S. L. 2010. Becoming institutional bodies: Socialization into a long-term care home. Journal of Aging Studies, 24, 278-291.

WOJGANI, H. \& HANSON, J. 2007. Extra care housing: a paradigm shift. Sixth International Space Syntax Symposium. Istanbul, Turkey.

WRIGHT-ST CLAIR, V. 2011. Being occupied with what matters in advanced age. Journal of Occupational Science, 19, 44-53. 